\title{
Inflorescence and Floral Development in Orchidantha maxillarioides (Lowiaceae)
}

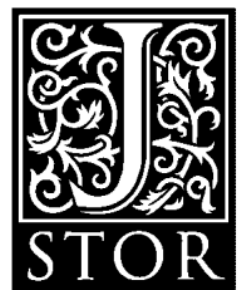

\author{
Bruce K. Kirchoff, Henning Kunze
}

International Journal of Plant Sciences, Volume 156, Issue 2 (Mar., 1995), 159-171.

Kirchoff, B. K. and H. Kunze. 1995. Inflorescence and Floral development in Orchidantha maxillarioides (Lowiaceae). International Journal of the Plant Sciences 156: 159-171.

Made available courtesy of University of Chicago Press:

http://www.iournals.uchicago.edu/doi/abs/10.1086/297237

Your use of the JSTOR archive indicates your acceptance of JSTOR' s Terms and Conditions of Use, available at http://www.jstor.org/about/terms.html. JSTOR' s Terms and Conditions of Use provides, in part, that unless you have obtained prior permission, you may not download an entire issue of a journal or multiple copies of articles, and you may use content in the JSTOR archive only for your personal, non-commercial use.

Each copy of any part of a JSTOR transmission must contain the same copyright notice that appears on the screen or printed page of such transmission.

International Journal of Plant Sciences is published by University of Chicago Press. Please contact the publisher for further permissions regarding the use of this work. Publisher contact information may be obtained at http://www.jstor.org/journals/ucpress.html.

International Journal of Plant Sciences

(C) 1995 University of Chicago Press

JSTOR and the JSTOR logo are trademarks of JSTOR, and are Registered in the U.S. Patent and Trademark Office. For more information on JSTOR contact jstor-info@ umich.edu.

(C)2001 JSTOR

http://www.jstor.org/ 
Int. J. Plant Sci. 156(2):159-171. 1995.

(C) 1995 by The University of Chicago. All rights reserved.

$1058-5893 / 95 / 5602-0003 \$ 02.00$

\title{
INHORESCENCEANDFLORALDEVELOPMENTIN ORCHIDANIHAMAXII LARIOIDES(LOWIACEAE)
}

\author{
BRUCE K. KIRCHOFF' AND HENNING KUNZE \\ Department of Biology, University of North Carolina at Greensboro, Greensboro, \\ North Carolina 27412-5001; and Klaperstadt 46, 32425 Minden, Germany
}

\begin{abstract}
The inflorescence of Orchidantha maxillarioides is similar to a richly branched, polytelic truncate synflorescence. It consists of two to three paracladia borne in the axils of the uppermost phyllomes of the shoot. Each paracladium consists of six bracts. The lowermost bract is the sterile prophyll. The second and third bracts subtend paracladia of the next higher order. The fourth bract subtends a single flower. The fifth and sixth bracts are initiated but do not complete development. Initiation of the paracladia in the axils of bracts 2 and 3 is acropetal, but their differentiation is basipetal. The flowers are trimerous, with a perianth differentiated into sepals and petals. One petal is enlarged to form a labellum. There are five stamens, one inserted opposite each perianth member except the labellum. The ovary is inferior and is closed by a prolongation many times the length of the locular region of the ovary. Floral organ initiation begins with the posterior sepals. The anterior sepal is formed slightly later, at the same time as the initiation of the corolla. The anterior petals arise from primordia that produce only these organs, while the posterior petal (the labellum) arises from a common petal/stamen primordium. The petal/stamen primordium separates into the labellum and the two posterior outer stamens. The anterior outer stamen is initiated slightly later, in the region between the anterior petals. Throughout these stages a floral cup forms below the floral parts. The two inner stamens are initiated simultaneously on the inner surface of this cup, near the insertion of the anterior petals. Three gynoecial primordia are initiated at the top of the floral cup in the region that will form the prolongation. The primordia extend proximally to form the
\end{abstract}

\section{Introduction}

The Lowiaceae are a poorly known monogeneric family of monocotyledons in the order Zingiberales. Other members of this order include the bananas (Musaceae), Heliconias (Heliconiaceae), and culinary gingers (Zingiberaceae). Although a good deal of attention has been directed to these other families, the Lowiaceae remain enigmatic. Major reasons for this include the restricted distributions of the species in southern China, Indochina, Malaya, and Borneo (Larsen 1993), the small size of the plants, the difficulty of seeing the flowers in the field (Keng 1969), and lack of economic importance of the family. To date, 10 species have been described in the genus Orchidantha (Larsen 1993).

Despite these impediments, knowledge of the Lowiaceae is important in reconstructing the phylogeny of the Zingiberales. As one of only eight families in the order, the Lowiaceae possess critical character states that influence the interpretation of characters used in phylogenetic reconstruction. For instance, the Strelitziaceae, Heliconiaceae, Musaceae, and Costaceae all posses columns of tissue that unite the locular region of the ovary with the perianth (Kronestedt and Walles 1986; Kirchoff 1992; Newman and Kirchoff 1992; Kress and Stone 1993; Kress et al.

'Author for correspondence and reprints.

Manuscript received July 1994; revised manuscript received October 1994.
1994). This tissue has been variously interpreted as a fusion product of the style and receptacle, as a solid column of tissue, as a perianth tube, and as an extension of the ovary (Kronestedt and Walles 1986; Kunze 1986; Kirchoff 1992; Kress and Stone 1993; Kress et al. 1994). A similar but much longer structure exists in the Lowiaceae. In this family the structure has been interpreted as a solid column of tissue, a calyx tube, a corolla tube, and a prolongation of the ovary (Ridley 1893; Lane 1955; Larsen 1961, 1973, 1983; Holtturn 1970; Kunze 1986). Developmental study of this structure in the Lowiaceae will help resolve its homologies. Because of the varying interpretations, the existence of this structure has not been recognized as a characteristic shared by all of the families of the banana group (Musaceae, Heliconiaceae, Strelitziaceae, Lowiaceae).

Inflorescence structure is another characteristic of potential importance in determining the phylogeny of the Zingiberales, yet inflorescence structure has played only a minor role in published phylogenies of the order (Dahlgren and Rasmussen 1983; Kress 1990). In families like the Lowiaceae, where the structure of the inflorescence has been difficult to interpret, it is important to verify published reports before inflorescence structure is used for phylogenetic reconstruction.

In this article we describe the structure and development of the inflorescence and flower of Orchidantha maxillarioides (Ridl.) K. Schumn. ${ }_{159} \mathrm{We}$ confirm published reports of inflorescence structure and elucidate the development of the 
inflorescence for future comparison with related families. Our study of flower development in this species is the first detailed report of floral development in the banana group of the Zingiberales. As such, it prepares the way for developmental study of the other families and may eventually lead to a better understanding of the relationship between flower development and evolution in this order.

\section{Material and methods}

Living material of Orchidantha maxillarioides (Ridl.) K. Schumn. was collected from the University of North Carolina at Greensboro (UNCG) greenhouse from a collection of Duke University greenhouses that had originated from the Royal Botanic Gardens at Kew. A voucher specimen is deposited at DUKE (Kirchoff 88-178). Supplementary plants were collected from Lyon Arboretum, Oahu, Hawaii (Lyon accession no. 76.0083) and from the Botanical Garden, Erlangen, Germany. Development was studied with the epi-illumination, light microscopy technique of Sattler (1968) and Posluszny et al. (1980) and with SEM. Material for epi-illumination study was fixed in FAA (Berlyn and Miksche 1976), dehydrated to $100 \%$ ethanol, and stained for several days to weeks in Johansen's Fast Green (Johansen 1940). Destaining was carried out in $100 \%$ ethanol for a period of from 2 to many days. Photographs were taken with Kodak Technical Pan Film on a Leitz Ortholux 2 photomicroscope equipped with an Ultropak illuminator.

Flowers to be sectioned were transferred to tertiary butyl alcohol and prepared using standard paraffin technique (Berlyn and Miksche 1976). Sections were cut at 5-10 Am on a Reichert-Jung 2040 Autocut microtome and mounted on slides using Bissing's modified Haupt's adhesive (Bissing 1974). The sections were stained in tannic acid/ferric chloride followed by safranin and fast green (Berlyn and Miksche 1976), dewaxed using ClearRite III in place of xylene, and mounted in Permount.

Specimens for observation by SEM were dissected, dehydrated in formaldehyde-dimethylacetal, and critical-point dried using $\mathrm{CO}_{2}$. Goldsputtered specimens were observed in the SEM at 10 or $20 \mathrm{kV}$.

\section{TERMINOLOGY}

The median plane of the flower bisects the inflorescence axis and the main axis of the flower. We refer to the side of the flower away from the inflorescence axis as anterior and the side adjacent to the axis as posterior. In this article, the anterior side is always oriented toward the bottom of the plate in polar views of developing flowers and in cross sections.
We follow Troll (1964) and Weberling (1989) for general inflorescence terminology and Kunze (1986) in modifying this terminology to fit the inflorescence of the Lowiaceae. Troll (1964) defines an inflorescence as a modified shoot system that serves the formation of flowers. Thus, inflorescence is a general term that applies to any aggregation of flowers. A paracladium is a lateral branch or branch system that repeats the structure of the main axis. Paracladia may be branched, the ramifications forming paracladia of the next higher order. Kunze (1986) uses the term special paracladium to refer to the paracladia of the Lowiaceae. Special paracladia differ from paracladia in having a fixed number of elements (bracts, higher-order branches, etc.) in each paracladium. In a normal paracladium the number of elements is correlated with the position of the paracladium in the inflorescence. The more distal (or higherorder) paracladia have fewer elements. A florescence is an indeterminate terminal flowering unit of an inflorescence. If the florescence terminates the main axis of the inflorescence, it is termed the main florescence, while a florescence that occurs as part of a paracladium is a coflorescence. Florescences may be composed of simple lateral flowers or of cymosely branched lateral elements called partial florescences. Since each florescence consists of more than one flower, it is a polytelic (many-flowered) axis. A synflorescence is an inflorescence that consists of a system of florescences. A polytelic synflorescence is an indeterminate inflorescence consisting of main and coflorescences, the coflorescences often arranged in paracladia. A polytelic truncate synflorescence is a polytelic synflorescence that lacks a main florescence.

Our investigation of inflorescence structure was conducted by Bruce Kirchoff independently of Henning Kunze's (1986) study in order to confirm his results.

\section{Results ORGANOGRAPHY}

Orchidantha maxillarioides is a small plant with short, richly branched stems (fig. 1). The leaves are distichous, with sheathing bases, relatively long petioles, and linear-elliptic blades. The leaves are inserted close together on the short aerial stems (fig. 1).

The inflorescence consists of repeated modules (special paracladia) borne in the axils of the uppermost two to three phyllomes of the vegetative axis (fig. 2). The proximal one to two of these phyllomes are foliage leaves with full blades. The most distal phyllome is often a leaf sheath with a long precursory tip.

The inflorescence is similar in structure to a richly branched, polytelic truncate synflorescence 


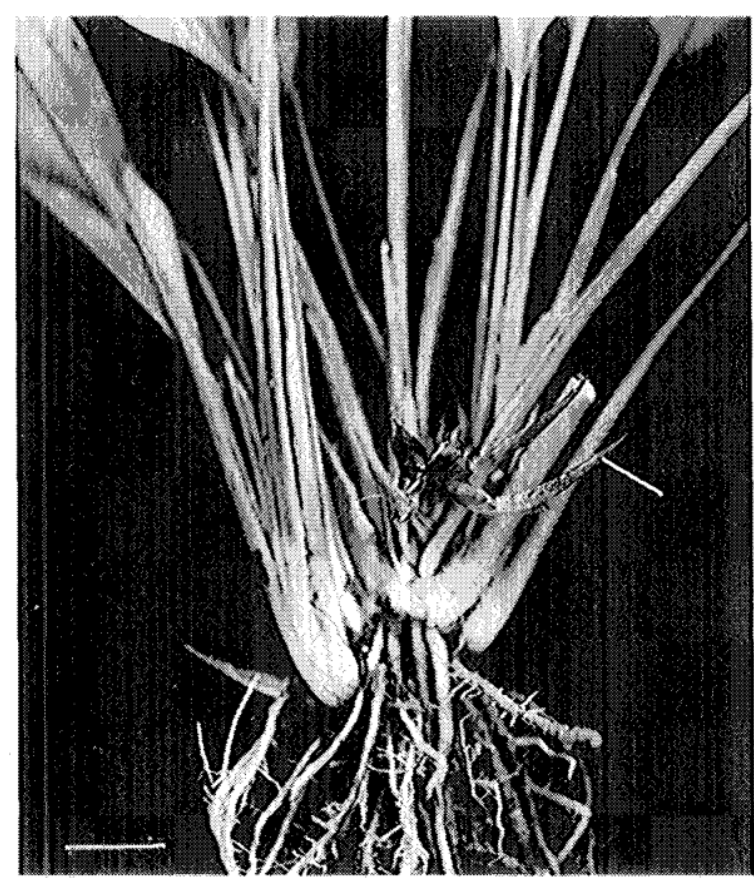

fig. 1 Orchidantha maxillarioides, showing long leaf sheaths and the position of a special paracladium (line), $B a r=2 \mathrm{~cm}$.

in that it lacks a main florescence and is richly branched from its lower nodes. Each special paracladium consists of an axis that bears four fully formed and two rudimentary bracts (fig. 2,sp). The first bract is an adaxially inserted prophyll. The second and third bracts are borne at approximately right angles to the prophyll and subtend special paracladia of the next higher order. The fourth bract subtends a single flower. There is no prophyll or bracteole on the axis that bears this flower. The fifth and sixth bracts remain rudimentary. In the mature inflorescence they lie adjacent to the flower, at the top of a long internode. Both of these bracts are sterile. Following their production, the apex stops growing and ceases the production of bracts.

The coflorescence consists of the uppermost three bracts of the special paracladium (bracts 46 ) and the single flower in the axial of bract 4 (fig. 2,co). Since rudimentary structures are not usually included when describing mature plant structure, we could also say that the coflorescence consists ofa single flower with its subtending bract.

The flowers are constructed according to the typical monocotyledon pattern, with organs arranged in whorls of three (fig. 3A). The perianth is differentiated into sepals and petals. The posterior petal is larger than the others and is referred to as the labellum. However, the labellum of the Lowiaceae is not homotopous and therefore is not homologous to the labellum of the Cannaceae, which is a petaloid androecial member. There are five stamens inserted opposite the se-

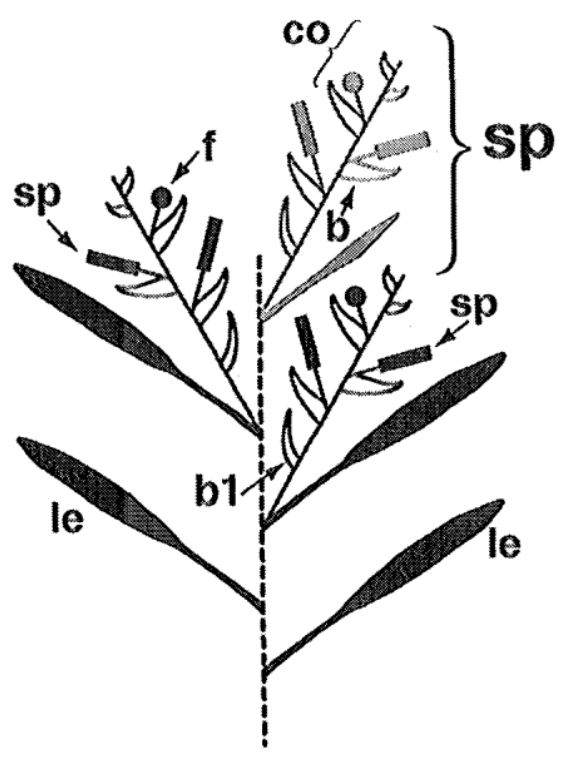

Fig. 2 Diagram of inflorescence structure. The special paracladia $(s p)$ occur in the axils of the uppermost full $(l e)$ or reduced (shaded) leaves. Shading of the uppermost phyllome and special paracladium indicates that these structures are not always present. The small bracts at the tip of each special paracladium are rudimentary bracts that do not complete development. The dashed line is the main axis of the plant that has been extended in this diagram. $b$, bract; $b 1$, prophyll; $c o$, coflorescence; $f$, flower.

pals and the two anterior petals. No stamen is found opposite the labellum (fig. 3A).

The ovary is trilocular and inferior. Ovules are numerous and are inserted on axile placentas. The apical closure of the locules is extended into
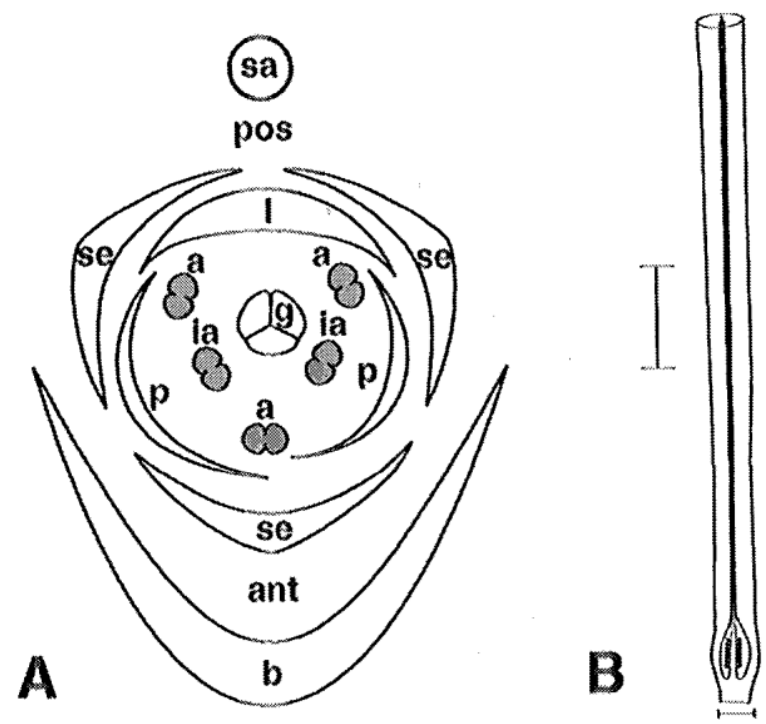

Fig. 3 Flower structure in Orchidantha maxillarioides, $A$, Floral diagram. $a$, outer stamen; $a n t$, anterior side of flower; $b$, subtending bract; $g$, gynoccium; $i a$, inner stamen; $l$, labellum; $p$, petal; pos, posterior side of flower; $s a$, special paracladium axis; se, sepal. $B$, Ovary with prolonged closure of the locules. Vertical bar $=1 \mathrm{~cm}$; horizontal bar $=2 \mathrm{~mm}$. 


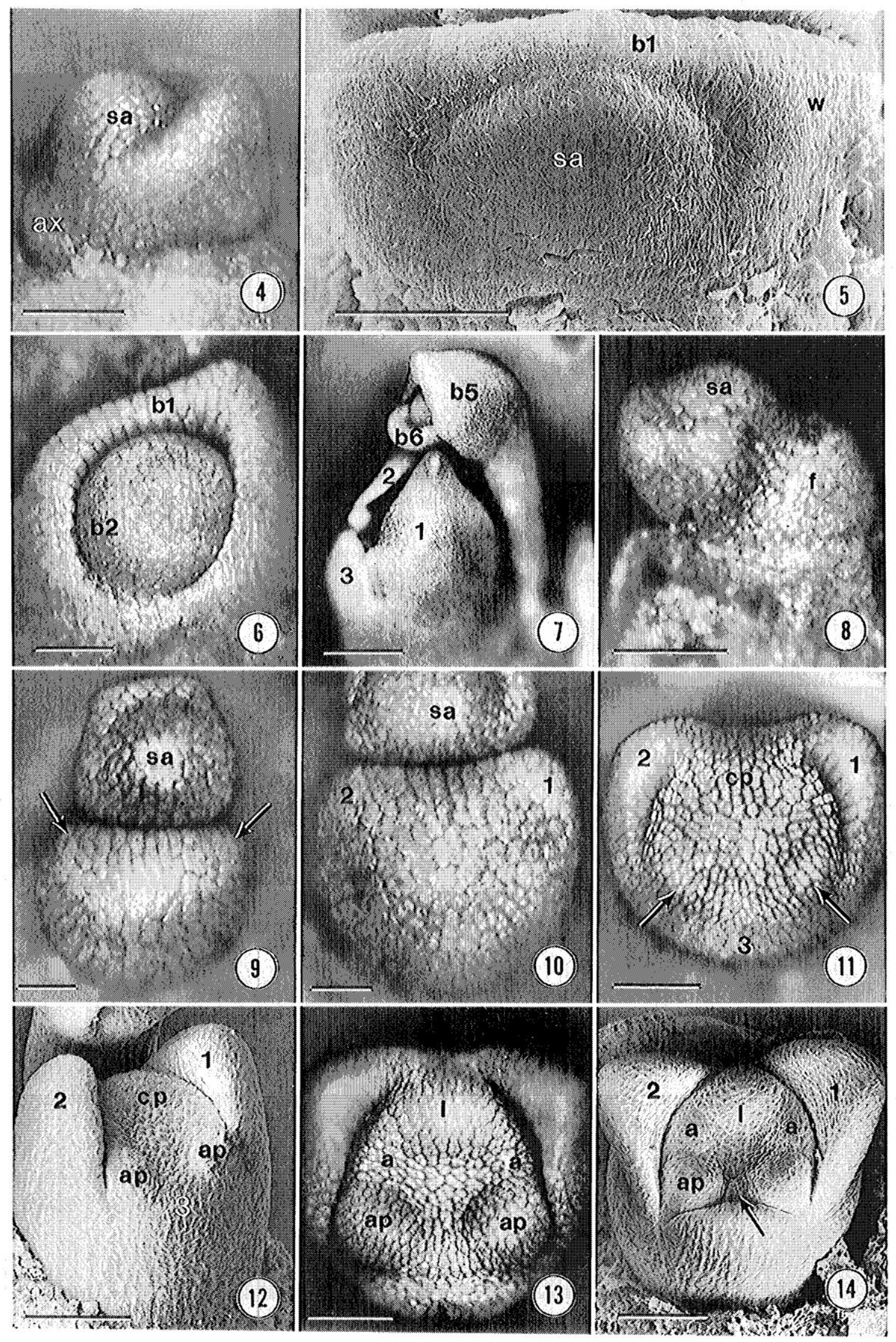


ovary proper (fig. 3B). In 0. maxillarioides the prolongation can exceed $5 \mathrm{~cm}$. The prolongation is traversed by the stylar canals, which arise from the tops of the locules, but is otherwise solid. There is no nectary anywhere in the flower, though nectary slits (exit pores) can be found above the prolongation, at the base of the style.

\section{NFLORESCENCEDEVELOPMENT}

The axillary buds that develop into special paracladia form in the axils of the second and third bracts on the special paracladium of the next lower order (fig. 4,ax). Although these buds are initiated in acropetal order, differentiation proceeds basipetally. The special paracladium in the axil of the third bract differentiates before the special paracladium in the axil of the second.

Prophyll initiation is more or less simultaneous around the periphery of the special paracladium apex (fig. 5,b1). The apex first enlarges tangentially and takes on the shape of the prophyll. The shoot apex and prophyll then separate, beginning with a slight depression near the tip of the prophyll and extending laterally around the apex. Immediately following initiation, the prophyll is symmetrical and is located between the apex and the axis of the special paracladium of next lower order (fig. 5). The lateral wings are the largest portion of the prophyll at this stage (fig. 5,w). As development proceeds, one of the lateral sides of the prophyll backing on the lower-order special paracladium may become pointed (fig. 6). This condition can persist to maturity.

The remaining bracts (second through sixth) are initiated in approximately the transverse plane of the new special paracladium, at a $90^{\circ}$ angle to the insertion of the prophyll (fig. $6, b 2$ ). The flower forms in the axil of the fourth bract. The first four bracts complete development and form part of the mature special paracladium. The remaining two bracts cease growth at an early point in their development (fig. 7,b5, b6) and remain rudimentary at maturity. The apex ceases growth soon after producing these bracts. A small knob consisting of the aborted apex and bracts 5 and 6 is present at the top of a long internode adjacent to the mature flower (fig. 7 for an immature stage). At maturity the flower and the apical complex are both enclosed by bract 4 .

\section{FLOWER DEVELOPMENT}

Flower development begins with the initiation of a bilaterally symmetrical primordium in the axil of the fourth bract (fig. 8, $f$ ). Growth of this flower primordium is rapid. It soon equals (fig. 8) or exceeds (fig. 9) the size of the special paracladium apex. The beginning of floral organogenesis is signaled by the flattening of the posterior side of the floral apex while the anterior side becomes more convex (fig. 9).

The first indication of the sepals are the angles at the junctions of the flat and convex sides of the apex. These angles mark the positions of the posterior sepals (fig. 9, arrows). During sepal initiation the floral apex enlarges and flattens through upward growth of the anterior side of the apex (figs. 9, 10). The sepal to the right of the medial plane of the flower is initiated slightly before the sepal to left of this plane. The anterior sepal is formed slightly later, at approximately the same time as the initiation of the corolla (figs. 11, 12). This sepal remains smaller than the posterior sepals throughout early floral development (fig. 7).

The corolla is formed from three primordia initiated at three positions alternating with the sepals (fig. 11). Initiation of these primordia is approximately simultaneous and occurs at about the same time as the initiation of the anterior sepal. The two anterior primordia produce only petals while the posterior primordium is a common petal/stamen primordium (figs. $1 \mathrm{l}, \mathrm{cp} ; 12, \mathrm{cp}$ ). Soon after its initiation the common primordium extends circumferentially around a portion of the apex. It occupies a greater portion of the apex than do the anterior petal primordia (fig. 12). As the primordia enlarge, they become better defined. The anterior petals become dorsiventral and the posterior petal becomes distinct from the

\footnotetext{
Figs. 4-14 Flower development through androecial initiation. Fig. 4, Special paracladium apex (sa) with axillary bud (ax) that will form a special paracladium of the next higher order. The bract subtending the bud has been removed. Bar $=100 \mu \mathrm{m}$. Fig. 5, Young special paracladium apex $(s a)$ following the initiation of the prophyll $(b 1)$. $w$, lateral wing of prophyll. Bar $=100$ $\mu \mathrm{m}$. Fig. 6, Special paracladium apex with first two bracts. $b 1$, prophyll; $b 2$, bract 2 . Bar $=100 \mu \mathrm{m}$. Fig. 7, Distal portion of special paracladium adjacent to older flower. 1, 2, 3, sepals labeled in order of initiation; $b 5$, bract $5 ; b 6$, bract 6 . Bar $=200$ $\mu \mathrm{m}$. Fig. 8, Young flower primordium $(f)$ adjacent to special paracladium apex $(s a)$. The subtending bract (bract 4$)$ has been removed. Bar $=100 \mu \mathrm{m}$. Figs. 9-14, Flower primordia. Fig. 9, Initial appearance of the sepals (arrows). sa, special paracladium apex. Bar $=50 \mu \mathrm{m}$. Fig. 10, Posterior sepal formation. 1, first-formed sepal; 2, second-formed sepal; sa, special paracladium apex. Bar $=50 \mu \mathrm{m}$. Fig. 11, Anterior sepal (3) and petal initiation. 1, 2, posterior sepals labeled in order of initiation; arrows $=$ anterior petals; $c p$, common petal/stamen primordium. Bar $=100 \mu \mathrm{m}$. Fig. 12, Oblique view showing the extent of the common petal/stamen primordium $(c p)$ in comparison with the anterior petal primordia $(a p) .1,2,3$, sepals labeled in their order of initiation. Bar $=100 \mu \mathrm{m}$. Fig. 13, Early stage of the separation of the labellum $(l)$ and posterior, outer stamen $(a)$. $a p$, anterior petals. Bar $=100 \mu \mathrm{m}$. Fig. 14, Separation of the common petal/stamen primordium and formation of anterior outer stamen (arrow). The posterior sepals $(1,2)$ have been pushed back to reveal the inner parts of the flower. $a$, posterior outer stamen; $a p$, anterior petal; $l$, labellum. Bar $=100 \mu \mathrm{m}$.
} 


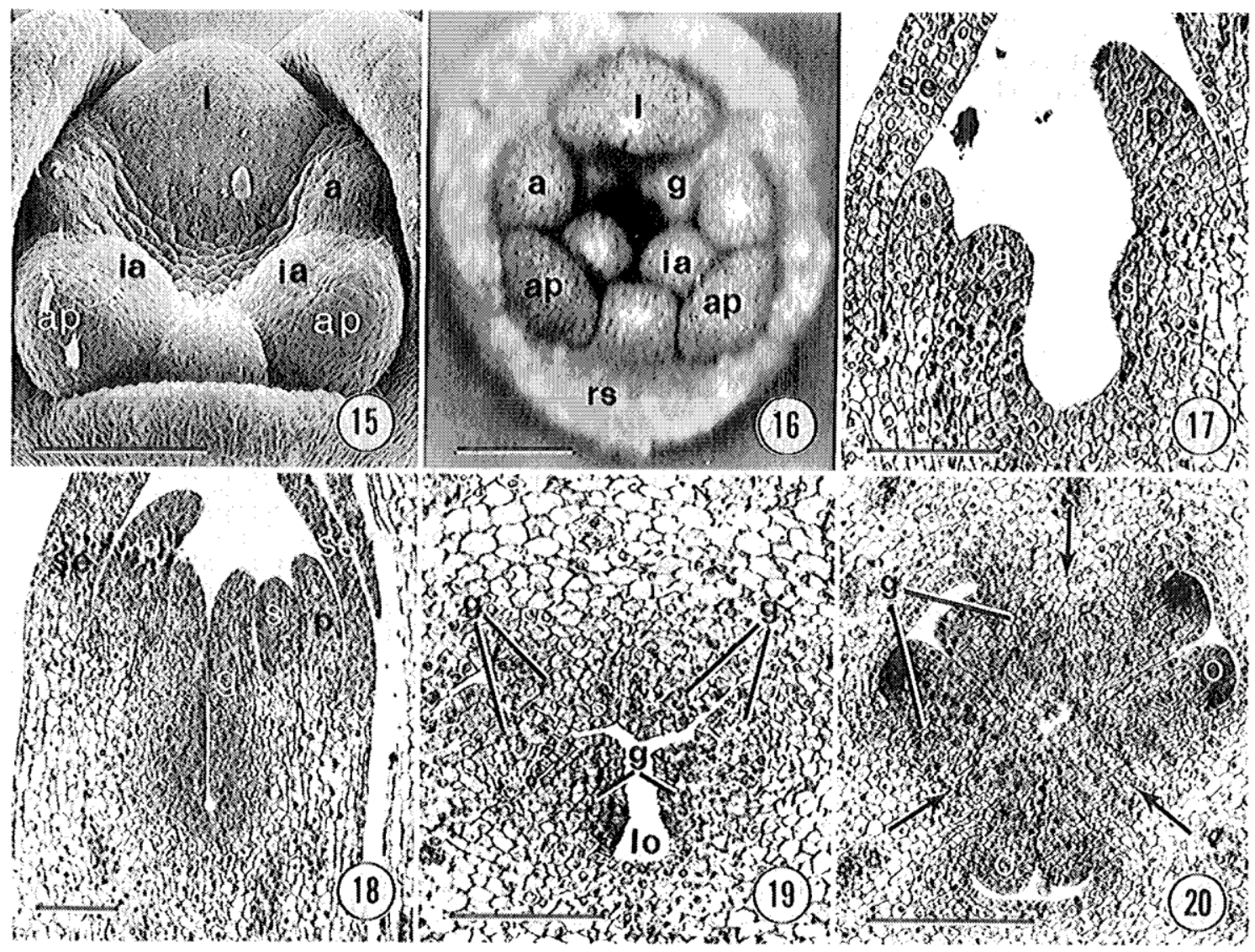

Flgs. 15-20 Flower development from inner androecial initiation to formation of the septa. Fig. 15, Initiation of the inner stamen $(i a)$ on the inner margin of the floral cup. $a$, outer stamen; $l$, labcllum; ap, anterior petals, Bar $=100 \mu \mathrm{m}$. Fig. 16, Gynoecial $(g)$ initiation. $a$, outer stamen; $i a$, inner stamen; $l$, labellum; $a p$, anterior petal; rs, removed sepal. $B a r=100 \mu \mathrm{m}$. Figs. 17, 18, Longitudinal sections. Fig. 17, Gynoccial $(g)$ initiation at the top of the floral cup. ia, inner stamen; $p$, petal; se, sepal. Bar $=50 \mu \mathrm{m}$. Fig. 18, Enlargement of the gynoecium through extension of the gynoecial primordia $(\mathrm{g})$ and intercalary growth. $p$, petal; $s$, stamen; se, sepal. Bar $=100 \mu \mathrm{m}$. Figs. 19, 20, Cross sections. Fig. 19, Three bilobed gynoecial primordia $(g)$ growing into the center of the floral cup in the locular region, $l o$, future site of a locule. Bar $=100 \mu \mathrm{m}$. Fig. 20, Fusion of gynoecial primordia $(g)$ to form the septa (arrows). $o$, ovule. Bar $=200 \mu \mathrm{m}$.

posterior stamen primordia (figs. 13, 14). The posterior petal primordium forms the labellum. The labellum is slightly larger than the anterior petals at all stages of development.

Two posterior, outer stamens are formed from the sides of the common primordium (fig. 13,a). During the initial phase of stamen formation the enlargement of the labellum outstrips the flanks of the common primordium, leaving the posterior stamens behind. Growth of these lateral regions produces the separate 'stamen primordia (fig. 14,a). The third outer stamen is formed between the two anterior petals (fig. 14, arrow). The initiation of this stamen slightly lags behind the posterior members of the outer androecial whorl. It appears at about the time the posterior members become distinct.

A floral cup develops below the insertion of the petals and outer stamens (figs. 14, 15). The cup unites all of the 'interior floral members and extends to just below the insertion of the sepals.

The two inner stamens are initiated simulta- neously on the inner surface of the floral cup, near the junction of the petals and the cup (fig. 15,ia). No stamen forms opposite the labellum (fig. 15). With continued growth, the floral cup deepens and the posterior sepals close over the top of the flower (fig. 7).

Three bibbed gynoecial primordia are initiated opposite the sepals. They form from the sides of the floral cup below the insertion of the other floral members (figs. 16, 17). The position where they are initiated forms the prolongation. Following their first appearance the regions of gynoecial initiation extend proximally into the floral cup, into the region that forms the locules and ovules (fig. 18). The gynoecial primordia also grow distally to form the style and stigma (fig. 18). The major portion of the ovary is formed through intercalary growth. We briefly describe gynoecial development beginning with the locular region and proceeding acropetally through the prolongation to the style and stigma.

In the locular region, three bibbed primordia 
grow into the center of the floral cup (fig. 19). The lobes of these primordia (figs. 19,g; 20,g) are longitudinally continuous with the margins of the folded style primordia (fig. 21). In the locular region, these lobes enclose the locules (figs. 19, 20). The septa arise through the close contact and fusion of the outer margins of these primordia (figs. 20, 21). Later, the primordia also fuse at the center of the ovary to form the central axis (fig. 20). Placentas and ovules form from the inner margins of the gynoecial primordia (fig. 20).

In the prolongation, radial growth of the bilobed gynoecial primordia proceeds more quickly than in the locular region (fig. 21). The primordia soon become closely appressed and fill the lumen of the floral cup (figs. 21, 22). The primordia fuse on all but their inner surfaces, which remain free and form the lining of the stylar canals (figs. 23,c; $24, c)$. The stylar canals form vertically above the locules (figs. 21, 24). Intercalary growth produces the majority of the prolongation. This is evident from the longitudinal lines of cells in the young prolongation (fig. 24, arrow).

Distally, the gynoecial primordia enlarge to fill the center of the flower. There are three style/ stigma primordia: two folded posterior primordia and one simple anterior primordium (figs. 21,g; $25, \mathrm{~g})$. With continued growth the posterior primordium also becomes folded (fig. 26). The apical portions of the primordia form the stigma, while the basal portions produce the style (figs. $22,26,27,28)$.

Fusions of the gynoecial primordia begin in the style at a point just above the attachment of the petals and stamens (fig. 27, arrow). Fusions occur both among adjacent primordia and between the appressed surfaces of a single primordium. An early stage of fusion among adjacent primordia is indicated by the crenelations on the surfaces of the primordia when they are separated (fig. $27, c r)$. A small slit remains unfused at the base of the style (fig. 28, arrow). This slit is in a position common for the exit pore of a septal nectary, although no nectaries are present in 0 . maxillarioides.

\section{Dlscussion}

INFLORESCENCE STRUCTURE

The inflorescence of the Lowiaceae has been described in the taxonomic literature as paniculate (Ridley 1893), cymose (Larsen 1961; Keng 1969), a branched cyme (Lane 1955; Larsen 1961), flowers solitary and borne from the rhizome $(\mathrm{Wu}$ 1964), a series of monochasial cymes (Holttum 1970), and a composite cincinnus of unknown structure (Larsen 1973). Tomlinson (1959) describes the inflorescence as cymose and the bracts as spirally arranged. Unfortunately, the Lowiaceae is one of the few families of the Zingiberales

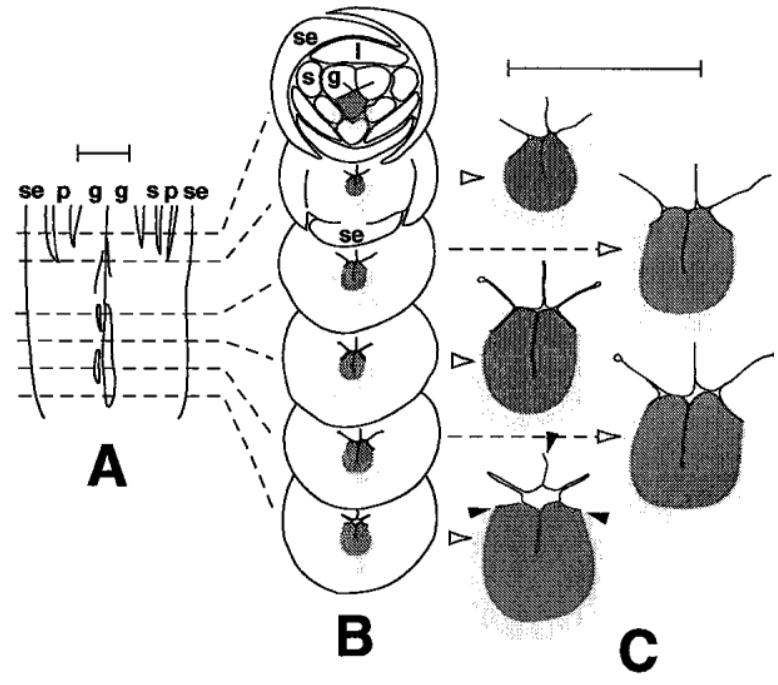

Fig. 21 Diagrams of a flower at an early stage of ovary development. The illustrated stage lies between those shown in figs. 18 and 22. $A$, Reconstruction of a longitudinal section showing levels of diagrams in parts B and C. $B$, Cross sections of the flower at levels indicated in $A$. One bilobed gynoecial primordium is shaded in each section. Except at the center of the ovary, the limits of the shaded areas are arbitrary. $C$, Enlargements of the gynoecial primordia in $B$. Adjacent bilobed primordia fuse to form the septa (solid arrowheads). Note that the gynoecial primordia are more closely appressed at the top of the ovary (prolongation) than at the bottom (locular region). It is not possible to determine the precise limits of the prolongation and locular region at this stage. $g$, gynoecial primordia; $l$, labellum; $p$, petal; $s$, stamen; se, sepal. Bars $=200 \mu \mathrm{m}$.

whose inflorescence does not contain a monochasial cyme. Thus, none of these descriptions does justice to inflorescence structure in the family.

Lane (1955), Larsen (1961), and Holttum (1970) are the taxonomists who have given the most detailed accounts of inflorescence structure in the Lowiaceae. Although differing in details, the descriptions of these authors are similar in the general structure of the inflorescence and include many of the features we describe in this study. The only difference between Larsen's (1961) diagrams of Orchidantha laotica and our description of Orchidantha maxillarioides is that the second bract of the paracladiurn is sterile in Larsen's (1961) diagrams and was found to be fertile in this study. This could be a specific difference between these two species. Lane (1955) and Holtturn (1970) incorrectly place the whole inflorescence on a lateral branch. They also state that the flower is terminal, not lateral (Lane 1955; Holttum 1970). Holttum (1970) specifically states that the most distal mature bract (i.e., bract 4 , the bract that subtends the flower) is sterile. Lane's (1955) diagram of inflorescence structure is difficult to interpret and does not seem to agree with his own descriptions, a point noted by Holttum (1970). 


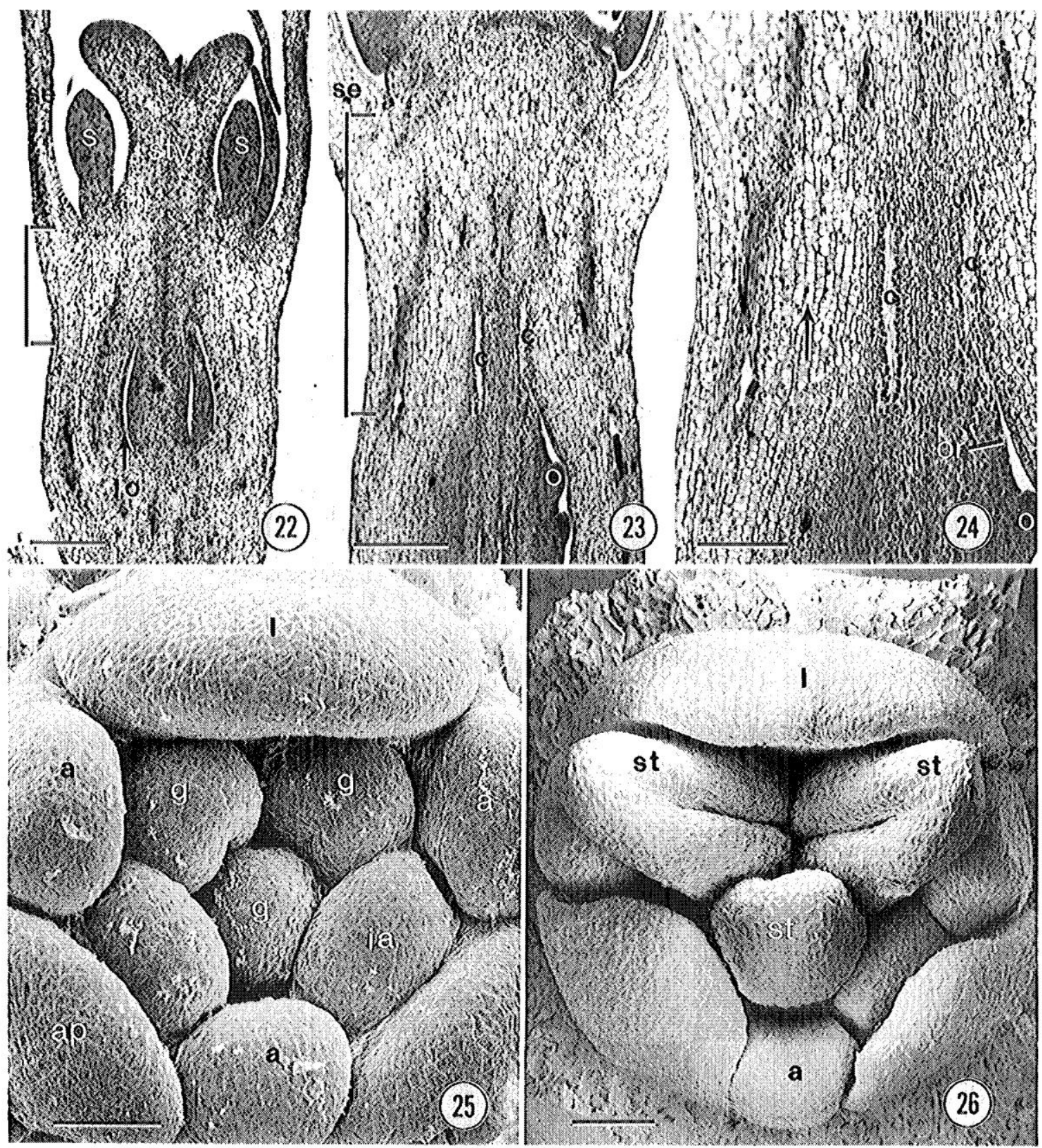

Figs. 22-26 Figs. 22-24, Longitudinal sections of prolongation development. Fig. 22, Formation of prolongation. bracket $==$ approximate limits of the prolongation; lo, loculc; s, stamen; se, sepal; sty, stylc. Bar $=300 \mu \mathrm{m}$. Fig. 23, Extension of prolongation and formation of ovules $(o)$. bracket $=$ approximate limits of the prolongation; $c$, stylar canal; se, sepal. $13 a r=300 \mu \mathrm{m}$. Fig. 24 , Enlargement of fig. 23 showing top of locular region and prolongation. Note the vertical files of cells arising from intercalary growth (arrow) and the origin of the stylar canals at the apex of the locules (or). $c$, stylar canal; $o$, ovule. Bar $=150 \mu \mathrm{m}$. Figs. 25 , 26, SEM. Fig. 25, Gynoccial primordia $(g)$ producing style and stigma. $a$, outer stamen; $i a$, inner stamen; $l$, labellum; $a p$, anterior petal. Bar $=50 \mu \mathrm{m}$. Fig. 26, Formation of the stigma $(s t), a$, outer stamen; $l$, labellum. Bar $=50 \mu \mathrm{m}$.

Kunze (1986) describes the inflorescence of 0 . maxillarioides in precise detail. Our description of inflorescence structure agrees with his in all respects.

There is no simple term in current taxonomic use that adequately describes inflorescence structure in Orchidantha. The most nearly correct term, a polytelic truncated synflorescence, is never used taxonomically. As a compromise, we suggest that the inflorescence be referred to as a truncated thyrse in future taxonomic publications.

\section{FLOWERSTRUCTURE}

Other than the nature of the prolongation, there has been little controversy over flower structure in the Lowiaceae. All but one description of flower structure in the family has noted the absence of the stamen opposite the labellum (Schumann 
1900; Winkler 1930; Lane 1955; Tomlinson 1959; Holum 1970; Kunze 1986; Kress 1990). The single exception is Larsen (1961), who describes two new species, Orchidantha siamensis and 0 . laotica, that have a small wartlike staminode replacing the sixth stamen. Despite Holttum's (1970) claim to the contrary, Larsen includes this staminode in his drawings of the species (Larsen 1961, figs. 2g, 4h). Holttum (1970) was unable to confirm the presence of this staminode in the species he saw personally (Orchidanthdfimbriata, Orchidantha longiflora, 0. maxillarioides), and we confirm its absence in 0 . maxillarioides. No one except Larsen (1961) has examined O. siamonis or 0. laotica for the presence of these staminodes. It may be that their presence is restricted to these species.

The lack of an antipetalous stamen is evidence for the phylogenetic placement of the Lowiaceae close to the Musaceae and Strelitziaceae, the only other families of the Zingiberales to lack this member of the inner whorl. The orders placed close to the Zingiberales and in which the sister groups of the Zingiberales will most likely be found (Bromeliales, Commelinales; Thorne 1992) all posses this stamen. In the Heliconiaceae, the other family traditionally placed close to the three listed above (the banana group), a member of the outer androecial whorl is replaced by a staminode (Eichler 1875; Kunze 1985; Kress 1990; Kirchoff 1991, 1992). All the members of the outer whorl are present in the Lowiaceae, Musaceae, and Strelitziaceae.

Although most families of the Zingiberales posses some type of nectary, nectaries are lacking in the Lowiaceae. Gynopleural nectaries (Smets and Cresens 1988) are found in the Musaceae, Heliconiaceae (Kirchoff 1992), and Strelitziaceae (Kronestedt and Wailes 1986), the three families that are closest to the Lowiaceae. The blind sutures found in 0 . maxillarioides are most likely a phylogenetic remnant of these nectaries.

In 0 . maxillarioides the position of the labellum with respect to the special paracladiurn axis differs between the primordial and the mature stages of flower development. At inception, the labellum is located posteriorly, adjacent to the axis of the paracladium (figs. 3A, 12, 15). At maturity, the labellum is oriented toward the earth, away from the paracladiurn axis (Ridley 1893, pl. LXVI; Schumann 1900, fig. 10C). The flower is thus resupinate at maturity (Schumann 1900, p. 8). Ridley (1893, p1. LXVI) shows twist marks on the prolongation, indicating that this structure is instrumental in reorienting the flower.

Drawings and photographs of other Orchidantha species show that the flowers of these species are not resupinate (0. longiflora [Keng 1969]; 0. laotica [Larsen 1961]; Orchidantha insularis, Orchidantha chinensis [Wu 1964]). The flowers of

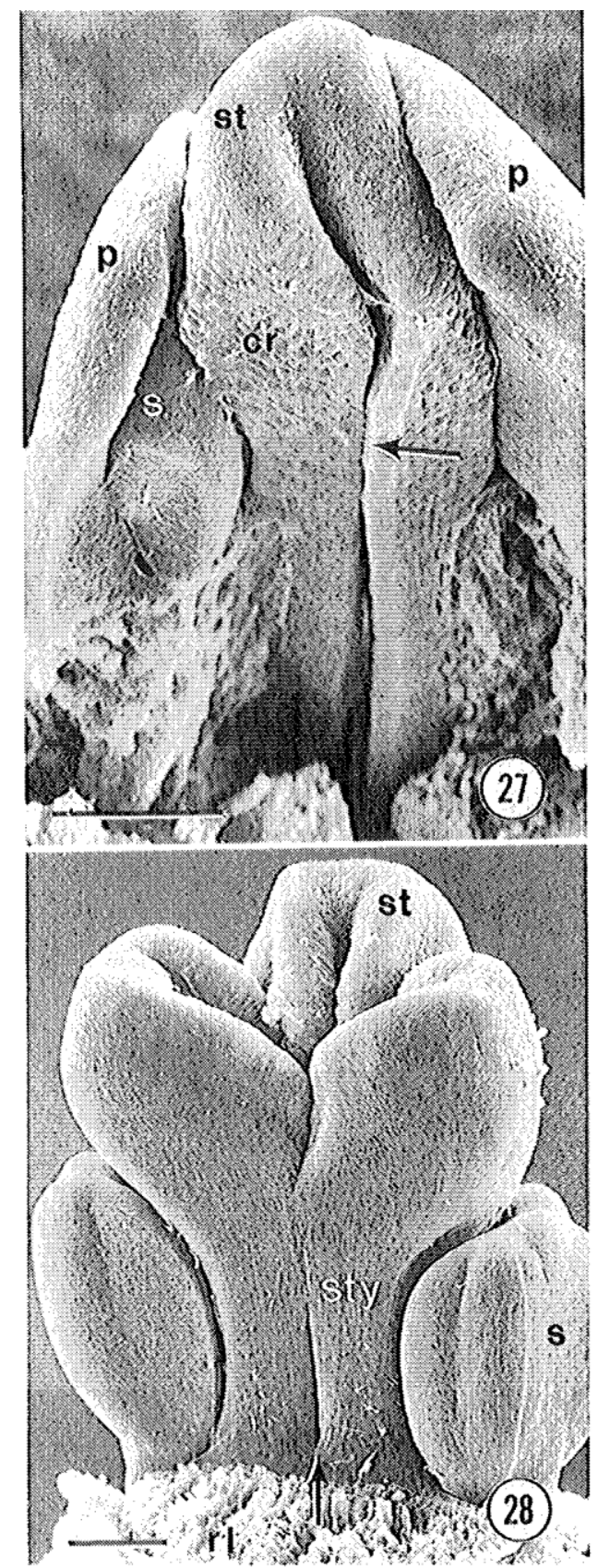

Figs. 27, 28 SEM of later stages of flower development. Fig. 27, Fusion of gynoecial primordium to itself (arrow) and to adjacent gynoecial primordia. The crenclations $(\mathrm{cr})$ on the surface of the primordium mark the initial sites of fusion to adjacent primordia. $p$, petal; $s$, stamen; $s t$, stigma. $B a r=100$ $\mu \mathrm{m}$. Fig. 28, Upper portion of the gynoecium showing differentiated style (sty) and stigma (st). Note the suture at the base of the style (arrow). $s$, stamen. Bar $=100 \mu \mathrm{m}$.

Orchidantha holttumii (Larsen 1993) appear to be rotated $90^{\circ}$ (half resupinate) when open. In making these interpretations we have assumed that the orientation of the labellum at initiation is the same as we have described for 0 . maxillarioides. 


\section{STRUCTUREANDFUNCTION OFTHEPROLONGATION}

The structure that we term the prolongation has been variously interpreted. As early as 1886 Brown (1886) notes that this structure is a solid column of tissue, not tubular as more recent authors have implied. Ridley (1893) also describes the solid composition of this structure but implies that it is part of the calyx. Schumann (1900), Winkler (1930), and Larsen (1961) describe the structure as a calyx tube, while Larsen (1973, 1983) describes it as a corolla tube. Tomlinson (1959) and Lane (1955) both recognize that the prolongation is solid; however, both describe it as composed of fused floral parts and neither mentions the presence of the stylar canals. Lane (1955) specifically states that it is "not a prolongation of the ovary." Holttum (1970), who was the first to correctly identify the prolongation as an extension of the ovary, does not mention the presence of the stylar canals. Kunze (1986) correctly interprets the prolongation as an extension of the ovary, notes that it contains a trilobed stylar canal, and also draws attention to the homology between the prolongation of the Lowiaceae and the corresponding region of Strelitzia reginae (Strelitziaceae).

Structures homologous to the prolongation of Orchidantha have been described in the Strelitziaceae (Kronestedt and Walles 1986; Kunze 1986; Kress and Stone 1993; Kress et al. 1994), Musaceae (Fahn et al. 1961; Fahn and Kotler 1972; Tilak and Pai 1974; Fahn and Benouaiche 1979; Kirchoff 1992), Heliconiaceae (Kirchoff 1992), and Costaceae (Newman and Kirchoff 1992). The prolongation of the Strelitziaceae is large, ca. one to two times the length of the locular region of the ovary (Kronestedt and Walles 1986; Kress and Stone 1993, fig. 1F; Kress et al. 1994, fig. 4). Those of the Heliconiaceae vary from simple closures of the ovary (Heliconia psittacorum) to structures about half the length of the locular region (Heliconia indica) (Kirchoff 1992). In the Musaceae and Costaceae the prolongations are shorter than the locular region and bear the nectaries (Kirchoff 1992; Newman and Kirchoff 1992). The structure of the nectaries in these two families is very different.

Kronestedt and Walles (1986) describe the prolongation in $S$. reginae (Strelitziaceae) and interpret it as a composite structure consisting of receptacular tissue surrounding and fused to the style. They base their interpretation on the anatomical zonation of the ovary and prolongation. Kirchoff (1992) criticizes this interpretation based on his study of the Heliconiaceae and Musaceae. The ovary of the Heliconiaceae also has histological zones, although with slightly different structures than in S. reginae. In Heliconia the zones are correlated with structural features of the fruit and, according to Kirchoff (1992), should not be interpreted as typological demarcations of the ovary. Similar correlations are found between the ovary and fruit anatomy in the Strelitziaceae (B. K. Kirchoff, unpublished data).

Kress and Stone (1993) and Kress et al. (1994) describe the prolongations of Phenakospermum guyannense and Ravenala madagascariensis (Strelitziaceae), respectively, in their studies of the pollination biology of these species. These species are the only representatives of their genera, and with Strelitzia constitute the whole family. In P. guyannense Kress and Stone (1993) describe the prolongation as a solid column of tissue arising from the fusion of the six perianth members. Kress et al. (1994) describe the prolongation of $R$. madagascariensis as a perianth tube.

As demonstrated here for 0 . maxillarioides, the prolongation is an extension of the normal closure of the inferior ovary. This interpretation is supported by a comparison with the Heliconiaceae and Musaceae (Kirchoff 1992). The range of prolongation lengths found in the Heliconiaceae, supplemented with the developmental evidence presented here for 0 . maxillarioides, demonstrates that the prolongation is homologous to the tissue closing an inferior ovary. Preliminary studies of flower structure and development in the Strelitziaceae also support this view (B. K. Kirchoff, unpublished data).

One function of the prolongation in the Strelitziaceae and Lowiaceae can be determined from studies of pollination biology, taxonomic descriptions, and personal observations. In the Strelitziaceae the prolongation serves to elevate the perianth while keeping the ovary protected within the tough bracts that characterize this family. In Strelitzia nicolai the flowers change their angle of alignment with respect to the enclosing bract over the 3 days that the flowers are open (Frost and Frost 1981). This emergence of the flower is facilitated by bending of the prolongation (B. K. Kirchoff, personal observation). It seems likely that the prolongation also provides protection for the ovules from the manipulation and probing of the Greater Bushbabies (Galago crassicaudatus) and various sunbirds that are the major pollinators of this species (Frost and Frost 1981). Protection from vervet monkeys (Cercopithecus aethiops) is not effective, as these visitors pull the whole flower out of the bract and chew on the nectary (Frost and Frost 1981).

In $P$. guyannense the prolongation bends to raise the floral parts out of the bract (Kress and Stone 1993). Bending continues throughout the single night that the flower is receptive, so that the perianth points toward the axis of the inflorescence by morning. The protective function of the prolongation is illustrated through a consid- 
eration of pollinator behavior (Kress and Stone 1993). The Microchiropterid bats (Phyllostomus bastatus, Phyllostomus discolor) that pollinate these flowers grasp the closed petals of the flower in their teeth and feet claws, tripping the flower and releasing the style, which falls limply to one side. The bats then thrust their heads to the nectar reservoir at the base of the corolla. This behavior is repeated up to 15 times during a single foraging bout. Tripped flowers are seldom visited after this initial bout. Baretailed woolly opossums (Caluromys philander) were also observed forcing their snouts into the nectar reservoir, though these organisms did not contact the stigma in the process (Kress and Stone 1993). It seems likely that the prolongation serves to separate the lower, ovule-bearing portions of the ovary from these rather violent behaviors.

Similar functions of the prolongation can be postulated for $R$. madagascariensis, which is pollinated by ruffed lemurs (Varecia variegata variegata) (Kress et al. 1994). In this species, an emerging flower does not open spontaneously but is pulled from its enclosing bract by the pollinator. The lemur grabs the perianth of the newly emerging flower with its teeth and pulls it from the bract without breaking off the flower. In this process, the flower springs open and releases the previously dehisced anthers. The lemur then pulls apart the lateral sepals and forces its snout into the nectar chamber at the base of the perianth (Kress et al. 1994). These manipulations leave the perianth pointing upward, approximately parallel to the florescence axis (Kress et al. 1994, fig. 2). Although Kress et al. (1994) do not report a role for the prolongation in this process, it seems likely that it provides both the elasticity necessary for the lemur to manipulate the flower and protection for the ovules, which remain enclosed in the bract.

It is likely that the prolongation of the Lowiaceae has similar roles as that of the Strelitziaceae. Our evidence for this conclusion is drawn primarily from taxonomic descriptions of species and from observations of 0 . maxillarioides. In a number of species the lower portion of the ovary is enclosed in tightly rolled bracts $(0$. maxillarioides [Ridley 1893, pl. LXVI; Schumann 1900, fig. 10C]; 0. longiflora [Schumann 1900, fig. 10A; Keng 1969, fig. 1]; O. fimbriata [Holttum 1970, pl. 1]; O. holttumii [Larsen 1993, fig. 2]). Although these bracts are much more fragile than those of the Strelitziaceae, they do provide some protection for the delicate lower portions of the ovary. In some species, the basal parts of the inflorescence are borne underground $(0$. longiflora [Keng 1969]; O. holttumii [Larsen 1993]), which serves as further protection for the ovules. The prolongation elevates the perianth above the bracts and presents the floral parts to pollinators. The resulting separation of the stigma and stamens from the ovules may also serve a protective function. Pollinators or floral predators could destroy the perianth, stamens, and stigma without harming the ovules. That floral damage is a possibility is indicated by the lack of nectar reward offered by the flowers and by preliminary observations of tree shrew visitations in Malaya (W. J. Kress, personal communication).

\section{FLOWERDEVELOPMENT}

Kunze (1986) is the only previous author who describes aspects of floral development in the Lowiaceae. Our observations agree with his in all but the sequence of sepal initiation. He describes sepal initiation as occurring in the order left, right, median when the flower is viewed from the anterior side (Kunze 1986). We found the sequence to be right, left, median.

Of the other families in the banana group of the Zingiberales (Musaceae, Heliconiaceae, Strelitziaceae, Lowiaceae), floral development has only been studied in the Musaceae. The most complete account of development is for Musa paradisiaca subsp. sapientum var Gros Michel (White 1928). The sepals arise from a marginal ring of tissue around the periphery of the flower primordium (White 1928). Following the sepals, the two posterior stamens of the outer ring form next, at the same time as the posterior petal. Thus, Musa shows a precocious development of the posterior side of the flower, as does 0 . maxillarioides. The third, anterior stamen of the outer whorl is now formed followed by the two anterior petals. The three gynoecial primordia arise as outgrowths at the base of the outer ring of stamens, just as they do in Orchidantha. As they grow upward they fuse to form the style and stigma. Fusion of these primordia is incomplete at the base of the style. The three sutures produced here are the openings of the gynopleural nectary, which is borne in the prolongation in the Musaceae (Kirchoff 1992).

Hannah (1916) focuses on the formation of the inferior ovary in $M$. sapientum, but gives few specific details for this species, merely stating that its early development is similar to Gladiolus gandavensis, Iris germanica, and Freesia reflecta, species which she also investigates. Drawing on these descriptions, we assemble the following brief picture of flower development in $M$. sapientum (Hannah 1916). The sepals form from a flat, broad floral apex. The stamens are formed next and, at the same time, the tissue below the sepals elongates to form a tubular ring surrounding a shallow cavity. The gynoecial primordia appear at the top of this cavity. Upward growth causes them to cover the cavity and produces the style and stigma. Growth of the primordia into the center of 
the cavity produces the septa. Hannah (1916) does not discuss the origin of the petals. The main difference between Hannah's (1916) and White's (1928) accounts is the shape of the floral apex at the time of sepal initiation, which Hannah (1916) describes as flat and White (1928) describes as having a central depression. In 0 . maxillarioides we found that the apex was dome-shaped at sepal initiation (fig. 10).

Fahn and Kotler (1972) investigate ovary development in Musa acuminata cv Dwarf Cavendish and show that the gynoecial primordia are initiated at the top of the floral cup. Further development takes place in the same manner as described by White (1928) and Hannah (1916), and is similar to the pattern described here for 0. maxillarioides. One exception to this statement concerns the formation of the gynopleural nectaries. In Musa the fusion of the gynoecial primordia to form the septa is incomplete in the prolongation (Fahn and Kotler 1972). The gynopleural nectaries develop from this region (Kirchoff 1992).

\section{PHYLOGENETICPOSITION}

The position of the Lowiaceae within the Zingiberales has remained a matter of debate to the present. Kress (1990) constructed a single most parsimonious phylogenetic tree based on 34 anatomical and morphological characters. In this analysis the Lowiaceae are the sister group of the Glade (((Marantaceae, Cannaceae) (Zingiberaceae, Costaceae)) Heliconiaceae). This placement is supported by three characters drawn from Tomlinson's (1959) anatomical study of the Musaceae sensu lato: asymmetric guard cells, leaf adaxial hypodermis of a single cell layer, and polyarch root stele. While Tomlinson's (1959) data were the best available when Kress (1990) published his analysis, Triplett and Kirchoff (1991) have since shown that the Heliconiaceae posses two cell layers in their adaxial hypodermis. Kirchoff also has unpublished data indicating that there is more variability in leaf guard cells than Tomlinson $(1956,1959)$ was aware of. Thus, the position of the Lowiaceae suggested by Kress (1990) may not be robust.

The most recent phylogenetic analysis of the Zingiberales, based on sequence data from the chloroplast gene that encodes the large subunit of ribulose bisphosphate carboxylase $(r b c L)$, yielded two equally parsimonious trees of 1,163 steps (Smith et al. 1993). These trees differ only in the relationship between two of the outgroups. The relationships among the taxa of the Zingiberales were identical in the two trees. However, when trees one step longer are considered, 62 equally parsimonious trees are found and when trees of two or fewer steps are included, 1,541 trees emerge (Smith et al. 1993).

Despite these problems, the analysis of Smith et al. (1993) raises an interesting possibility for the placement of the Lowiaceae. In the most parsimonious trees the Lowiaceae are the sister group of the Strelitziaceae. This relationship was also suggested by Dahlgren and Rasmussen (1983), but as Kress (1990) points out, Dahlgren and Rasmussen's (1983) data are consistent with several topologies, not just the single one they present as the phylogeny of the order. In the remaining portion of this article we consider the contribution of inflorescence and floral structure to choosing between these two alternative placements of the Lowiaceae. Floral development in the Strelitziaceae, Musaceae, and Heliconiaceae is too poorly known to allow the use of developmental characters in this analysis.

The data presented here with the most potential to be phylogenetically informative are the structure of the inflorescence and the existence of the prolongation. Among the taxa traditionally placed closest to the Lowiaceae (Musaceae, Heliconiaceae, and Strelitziaceae), the only family that bears a major inflorescence component in an axillary position is the Strelitziaceae. In this family both Ravenala and Strelitzia (Schumann 1900; Fisher 1976; Kunze 1986) bear axillary paracladia. Each paracladium is composed of a number of distichous bracts, the lowermost of which are sterile while the more distal form a coflorescence and subtend modified cincinni (Schumann 1900; Kunze 1986). The presence of a terminal inflorescence in Phenakospermum (Strelitziaceae) is most likely an autapomorphy of the genus (Kress et al. 1994). In the Lowiaceae, the special paracladia are composed of four mature bracts and one flower. The first bract is the sterile prophyll, the second and third bracts subtend paracladia of the next higher order, and the fourth bracts subtends a single flower (Kunze 1986). The possession of paracladia in these two families may be an indication of common ancestry. However, whether their possession results from synapomorphy, symplesiomorphy, or homoplasy must await a complete phylogenetic analysis of the order.

The prolongation of the ovary is most strongly developed in the Strelitziaceae and Lowiaceae. While this structure is present in the Musaceae, Costaceae, and some Heliconiaceae, its presence in the former two families is closely connected to the presence of the nectary in this region. The prolongation of the Heliconiaceae is the least well developed of the families of the banana group. In most species that have been investigated it is less than $2 \mathrm{~mm}$ long (Kirchoff 1992). The presence of the prolongation in the Strelitziaceae and Lowiaceae is correlated with the method of floral presentation in these families and, at least in the Strelitziaceae, with pollinator behavior. These similarities support the placement of the Lowiaceae as the sister group of the Strelitziaceae. We 
did not find any new evidence to support the placement of the Lowiaceae as the sister group of the Glade (((Marantaceae, Cannaceae) (Zingiberaceae, Costaceae)) Heliconiaceae).

\section{Adknowledgments}

We thank Professor A. Weber, Institute of Botany, Vienna, Austria, and Professor H. Uhlarz, Institute of Botany, Kiel, Germany, for the use of the SEM at their institutions. We also thank Winnell Newman for sectioning the material used in this study, the staff of the Duke University Greenhouses for donating the plants, and Valerie Ward and Daniel Smith for printing the plates. A portion of the work for this article was completed while Bruce Kirchoff was a research associate at Fairchild Tropical Garden, Miami, Florida. This article is based on work supported by the National Science Foundation under grants BSR-8307103 and BSR-8800178 and by a UNC Greensboro Research Council Grant to Bruce Kirchoff.

\section{Literaturecited}

Berlyn GP, JP Miksche 1976 Botanical microtechnique and cytochemistry. Iowa State University Press, Ames. 326 pp.

Bissing DR 1974 Haupt's gelatin adhesive mixed with formalin for affixing paraffin sections to slides. Stain Technol 49:116-117.

Brown NE 1886 Orchidantha borneensis, a new genus of Scitamineae. Gard Chron NS 26:519.

Dahlgren RMT, FN Rasmussen 1983 Monocotyledon evolution: characters and phylogenetic estimation. Evol Biol 16:255-395.

Eichler AW 1875 Blüthendiagramme construirt und erläutert. Engelmann, Leipzig.

Fahn A, P Benouaiche 1979 Ultrastructure, development and secretion in the nectary of banana flowers. Ann Bot 44: 85-93.

Fahn A, N Klarman-Kislev, D Ziv 1961 The abnormal flower and fruit of May-flowering Dwarf Cavendish bananas. Bot Gaz 123:116-125.

Fahn A, M Kotler 1972 The development of the flower and nectary of the Dwarf Cavendish banana. Pages 153-169 in YS Murty, BM Johri, HY Mohan Ram, TM Varghese, eds. Advances in plant morphology. Santa Prakashan, Meerut, India.

Fisher JB 1976 Development of dichotomous branching and axillary buds in Strelitzia (Monocotyledoneae). Can J Bot 54:578-592.

Frost SK, PGH Frost 1981 Sunbird pollination of Strelitzia nicolai. Oecologia 49:379-384.

Hannah M 1916 A comparative study of epigyny in certain monocotyledons and dicotyledons. Trans Am Microsc Soc 35:207-230.

Holttum RE 1970 The genus Orchidantha (Lowiaceae). Gard Bull (Singapore) 25:239-247.

Johansen DA 1940 Plant microtechnique. McGraw-Hill, New York.

Keng H 1969 Notes on the flowers of Orchidantha longiflora (Lowiaceae). Gard Bull (Singapore) 24:347-349.

Kirchoff BK 1991 Homeosis in the flowers of the Zingiberales. Am J Bot 78:833-837.

1992 Ovary structure and anatomy in the Heliconiaceae and Musaceae (Zingiberales). Can J Bot 70:24902508.

Kress WJ 1990 The phylogeny and classification of the Zingiberales. Ann Mo Bot Gard 77:698-721.

Kress WJ, GE Schatz, M Andrianifahanana, HS Morland 1994 Pollination of Ravenala madagascariensis (Strelitziaceae) by lemurs in Madagascar: evidence for an archaic coevolutionary system? Am J Bot 81:542-551.

Kress WJ, DE Stone 1993 Morphology and floral biology of Phenakospermum (Strelitziaceae), an arborescent herb of the Neotropics. Biotropica 25:290-300.

Kronestedt E, B Walles 1986 Anatomy of the Strelitzia regime flower (Strelitziaceae). Nord J Bot 6:307-320. Kunze H 1985 Die Infloreszenzen der Marantaceen und ihr Zusammenhang mit dem Typus der Zingiberales-Synfloreszenz. Beitr Biol Pflanz 60:93-140.
1986 Infloreszenz-und Blütenmorphologie von $\mathrm{Or}$ -

chidantha maxillarioides (Ridl.) K. Schumn. (Lowiaceae). Beitr Biol Pflanz 61:221-234.

Lane IE 1955 Genera and generic relationships in Musaceae. Mitt Bot Staatssamml München 2:114-131.

Larsen K 1961 New species of Veratrum and Orchidantha from Thailand and Laos. Bot Tidsskr 56:345-350. 1973 A new species of Orchidantha (Lowiaceae) from

Vietnam. Adansonia, ser 2,13:481-482. 1983 Lowiaceae. Pages 147-150 in J-F Leroy, ed. Fiore du Cambodge du Laos et du Viet-Nam. Muséum National d'Histoire Naturelle, Paris.

1993 A new species of Orchidantha (Lowiaceae) from Borneo. Nord J Bot 13:285-288.

Newman SW, BK Kirchoff 1992 Ovary structure in the Costaceae (Zingiberales). Int J Plant Sci 153:471-487.

Posluszny U, MG Scott, R Sattler 1980 Revisions in the technique of epi-illumination light microscopy for the study of floral and vegetative apices. Can J Bot 58:2491-2494.

Ridley HN 1893 On the flora of the eastern coast of the Malay Peninsula. Trans Linn Soc Lond, ser 2, Bot 3:267408, pls LXI-LXVI.

Sattler R 1968 A technique for the study of floral development. Can J Bot 46:720-722.

Schumann K 1900. Musaceae. Pages 1-45 in A Engler, ed. Das Pflanzenreich IV. Vol 45. Engelmann, Leipzig.

Smets EF, EM Cresens 1988 Types of floral nectaries and the concepts "character" and "character-state"- a reconsideration. Acta Bot Neerl 37:121-128.

Smith JF, WJ Kress, EA Zimmer 1993 Phylogenetic analysis of the Zingiberales based on $r b c L$ sequences. Ann Mo Bot Gard 80:620-630.

Thorne RF 1992 An updated phylogenetic classification of flowering plants. Aliso 13:365-389.

Tilak VD, RM Pai 1974 The floral anatomy of Ensete superbum (Roxb.) Cheesm. Proc Indian Acad Sci Sect B 80: 253-261.

Tomlinson PB 1956 Studies in the systematic anatomy of the Zingiberaceae. Bot J Linn Soc 55:547-592.

1959 An anatomical approach to the classification of the Musaceae. Bot J Linn Soc 55:779-809.

Triplett JK, BK Kirchoff 1991 Lamina architecture and anatomy in the Heliconiaceae and Musaceae (Zingiberales). Can J Bot 69:887-900.

Troll W 1964 Die Infloreszenzen: Typologie und Stellung im Aufbau des Vegetationskörpers. Vol 1. Gustav Fischer, Stuttgart.

Weberling F 1989 Morphology of flowers and inflorescences. Cambridge University Press, Cambridge.

White PR 1928 Studies of the banana: an investigation of the floral morphology and cytology of certain types of the genus Musa L. Z Zellforsch Mikrosk Anat 7:673-733.

Winkler H 1930 Musaceae. Pages 505-541 in A Engler, ed. Die Natürlichen Pflanzenfamilien. Engelmann, Leipzig. 